\title{
DIREITO DOS EMPREGADOS PÚBLICOS CELETISTAS NOMEADOS PARA CARGO EM COMISSÃO AO RECEBIMENTO DO FGTS
}

\author{
Paula dos Santos Bigoli, Mari Ângela Pelegríni \\ Universidade do Oeste Paulista - UNOESTE, curso de Direito, Presidente Prudente, SP. E-mail: \\ maripelegrini@uol.com.br
}

\section{RESUMO}

Este artigo conceitua o empregado público celetista e o analisa quando atuante em cargos comissionados. À luz do ordenamento jurídico brasileiro avalia o posicionamento majoritário dos Tribunais, expõe os direitos devidos a estes trabalhadores, analisando, por fim, se há compatibilidade entre exercer cargo em comissão e receber as contribuições referentes ao Fundo de Garantia do Tempo de Serviço - FGTS. Conclui que não existe previsão legal que vede o pagamento do FGTS nessas situações, de modo que, em tese, seria ilegal, pelas razões delineadas, não efetuar o pagamento do direito garantido ao trabalhador, nestas condições.

Palavras-chave: FGTS. Empregado público. Celetista. CLT. Cargo comissionado.

\section{RIGHT OF PUBLIC EMPLOYEES CLT NOMINATED FOR POSITION IN COMMITTEE OF THE FGTS PERCEPTION}

\begin{abstract}
This article conceptualizes the CLT public employee and analyzes him when acting in commissioned positions. According to the Brazilian legal system and the major court decisions, setting out the duties owed to these employees, analyzing for compatibility between the performance of a commission office and receive contributions for the Service Time Guarantee Fund - FGTS. It concludes that there is no legal provision that prohibits the payment of FGTS in these situations, so it is illegal do not pay the guaranteed right to the employee.
\end{abstract}

Keywords: FGTS. Public employee. CLT employee. CLT. Commissioned position 


\section{INTRODUÇÃO}

Os empregados públicos não são amparados por estatuto como os servidores públicos contratados pelo regime estatutário, e sim pela Consolidação das Leis do Trabalho - CLT e, a princípio, fazem jus a todos os direitos garantidos aos trabalhadores do ramo privado que também são conduzidos pelo regime celetista.

Não obstante, é corriqueira a nomeação destes empregados para o exercício, ainda que de forma interina ou não, nos chamados cargos em confiança ou cargos em comissão, que são aqueles direcionados a direção, chefia e assessoramento.

Ingressando, pois neste regime de contratação na administração, para exercerem tais cargos em comissão, normalmente vinculados pela indicação política, em mandatos predefinidos, em demonstrando sua competência, podem ali permanecer por longos anos.

Ocorre que, ao tomar posse desses cargos, o empregador menos esclarecido, não raro, entende ser indevido o pagamento das parcelas relativas ao Fundo de Garantia por Tempo de Serviço - FGTS, que é um instituto de proteção ao trabalhador, diante da inexistência da estabilidade no ordenamento jurídico brasileiro.

Assim, deixam de efetuar os depósitos devidos, a partir da data do efetivo exercício do cargo de confiança, normalmente ao argumento de que no exercício do cargo em comissão, a exemplo dos contratos por prazo determinado, não existe uma expectativa de manutenção do emprego e, por tabela, a necessidade de um fundo garantidor, ou a indenização acrescida ao final em eventual dispensa, que não será uma surpresa.

Cancelam, pois, unilateralmente, a continuidade dos depósitos e respectivas prestações, segundo a corrente de pensamento que se defende, injustificadamente, retirando do trabalhador direito garantido e reafirmado por significativa parcela do ordenamento jurídico, com respaldo no Poder Judiciário.

Diante da lesão causada a todos estes trabalhadores, torna-se mister compreender e analisar os fundamentos que regem o assunto, buscando o norte da justiça para solucionar a questão e entender qual deve ser o posicionamento adequado, sendo este, portanto, o objetivo do presente artigo.

Por fim, ressalte-se que estudo foi desenvolvido a partir de levantamento bibliográfico e documental. Os métodos aplicados foram o dedutivo e o dialético, o que permitiu uma discussão e análise entre os fatos apresentados de modo a interpretar possíveis conclusões. 


\section{EMPREGADO PÚBLICO}

Empregado público é a pessoa física que presta serviços à administração direta ou indireta com vínculo empregatício conduzido pelo regime celetista, previsto na CLT (Consolidação das Leis do Trabalho).

Difere-se do servidor público, pois este está sujeito ao regime estatutário e ocupa cargo público, além de ser beneficiário de estabilidade, prevista no artigo 41 da Constituição Federal de 1988 (NADAL, 2015).

Nesse diapasão, se pronuncia Oliveira (2014, s.p.):

O regime do emprego público é constituído por normas previstas na Lei 9.962/2000, bem como pela Consolidação das Leis do Trabalho (CLT) e legislação correlata. Em outras palavras: o regime do emprego público determina, basicamente, a aplicação do regime celetista aos empregados públicos federais integrantes das entidades públicas, com a ressalva de que serão observadas as normas específicas previstas na citada Lei.

A Lei no 9.962/2000 (que disciplina o regime de emprego público) limitou a rescisão do contrato de trabalho por ato unilateral à apenas quatro hipóteses taxativas, criando assim uma estabilidade equiparada à do servidor público, entendimento este consolidado pela súmula 390 do TST (Tribunal Superior do Trabalho), que prevê que "o servidor público celetista da administração direta, autárquica ou fundacional é beneficiário da estabilidade prevista no art. 41 da CF/1988" (GOMES, 2012).

Em virtude de ser submetido ao regime celetista, o vínculo entre o empregado público e o Estado (que é contratual), também tem a proteção das legislações correlatas à CLT, incluindo a Lei no 8.036/1990, que dispõe sobre o FGTS (Fundo de Garantia do Tempo de Serviço).

\section{EMPREGADO PÚBLICO NOMEADO PARA CARGO EM COMISSÃO}

A Constituição Federal em seu artigo 37, inciso II, impôs a obrigatoriedade de aprovação em concurso público de provas ou de provas e títulos para a investidura em cargo ou emprego público.

Não obstante, foi estabelecida apenas uma exceção: as nomeações para cargo em comissão, declarado em lei de livre nomeação e exoneração. Estes cargos se destinam apenas às atribuições de direção, chefia e assessoramento, conforme estabelece o artigo 37, inciso $V$ do mesmo Texto Constitucional.

No tocante a esta disposição, elucida Santos (2012, p. 266): 
O cargo é de livre nomeação porque a autoridade, com base unicamente no seu poder discricionário, escolhe e nomeia livremente a pessoa que ocupará o cargo de confiança; livre exoneração porque o ocupante do cargo, devido à natureza transitória deste, pode ser exonerado livremente a qualquer momento pela autoridade competente, sem necessidade sequer de motivar o ato, ou seja, de expor os motivos da dispensa.

O cargo em comissão pode ser ocupado por pessoas que já possuem, ou não, vínculo com a Administração (ALEXANDRE, 2015).

Feitas estas considerações, interessante destacar a situação em que o empregado público (que já possui vínculo com a Administração) é nomeado para cargo em comissão, objeto deste estudo.

Ao assumir o cargo em comissão, o contrato de trabalho do empregado público fica suspenso. No entanto, o vínculo continua a ser conduzido pelo regime celetista, inclusive gerando contribuição junto ao RGPS (Regime Geral de Previdência Social).

Está ai que reside o ponto central. Teria este empregado direito de ter ou continuar tendo em sua conta vinculada, até a dispensa, destina para recepcionar os depósitos do FGTS?

Insta destacar que o empregado, fato incontroverso, pode ser exonerado do cargo comissionado injustificadamente e a qualquer momento. Voltará a atuar na sua função de origem, levantando o cerne da questão. Se já sabe que pode ser exonerado no regime da CLT, impende investigar se teria ele direito aos depósitos do período e o acréscimo de $40 \%$ previsto na Constituição Federal.

Mas, antes de continuar esta investigação, interessante revisitar o instituto do FGTS, em sua base legal, ainda que brevemente, o que será feito no próximo tópico.

\section{FUNDO DE GARANTIA DO TEMPO DE SERVIÇO - FGTS}

O FGTS (regulamentado pela Lei no 8.036/1990) é o recolhimento obrigatório a todo empregador, no importe de $8 \%$ da remuneração mensal do empregado, que surgiu em substituição a indenização por tempo de serviço e a estabilidade decenal.

Assim conceitua Resende (2014, s.p.):

O Fundo de Garantia do Tempo de Serviço -FGTS é um fundo formado por recolhimentos mensais incidentes sobre a remuneração do empregado, efetuados em conta vinculada aberta na Caixa Econômica Federal - CEF em nome do trabalhador, que visa principalmente à subsistência do trabalhador durante o período de desemprego, em substituição à antiga indenização celetista prevista no art. 478 da CLT. 
Neste âmbito, Saraiva (2012) explica que “é contribuinte do FGTS qualquer empregador, pessoa física ou jurídica, de Direito Público ou Privado, que admitir trabalhadores regidos pela CLT". Sendo assim, é indiscutível que o empregado público celetista faz jus ao direito constitucional de ter acesso ao FGTS, garantido pelo artigo 7으, inciso III, da Carta Magna.

\section{EMPREGADO PÚBLICO EM CARGO COMISSIONADO E O PAGAMENTO DO FGTS}

Como já mencionado, os empregados públicos podem ser nomeados a assumir cargo em comissão, sem no entanto alterar o regime celetista, inicialmente escolhido pelo empregador. Sucede que existem empregadores que ao nomearem o empregado para cargo comissionado, cessam o pagamento das parcelas do FGTS, extraindo-lhe este direito sob a justificativa de haver incompatibilidade entre o FGTS e o cargo em comissão.

Indubitável é que este entendimento perdura desamparado por qualquer fundamento legal, conforme se expõe a seguir.

Ao se tornar um empregado comissionado, o trabalhador não altera seu regime de contratação a ponto, por exemplo de ficar protegido como se fosse um servidor público amparado por estatuto próprio, no chamado regime estatutário. Tampouco deixa de ser considerado um empregado celetista.

É bem verdade, que a única mudança é a função que este empregado vai desempenhar, ou em alguns casos, o que muda é apenas o nome do cargo.

Por outro lado, é de se verificar, também, que o artigo 15, parágrafo 2 o da Lei 8.036/1990 determina que o servidor público, sujeito a regime jurídico próprio, não é considerado trabalhador, de modo que não tem direito ao FGTS.

Nesta vereda, a CLT em seu artigo 7ํ, alínea "d", exclui da sua proteção somente os "servidores de autarquias paraestatais, desde que sujeitos a regime próprio de proteção ao trabalho, que lhes assegure situação análoga à dos funcionários públicos".

Contudo, se o empregado comissionado não passa a ser protegido por um estatuto, ou seja, não se torna um servidor público, conclusão lógica é que não poderia deixar de ter direito ao recolhimento fundiário, pois continua a ser um trabalhador celetista.

Nesta esteira, é conveniente demonstrar o posicionamento favorável ao entendimento acima esposado. De acordo com a mais alta Corte Trabalhista, o Tribunal Superior do Trabalho TST, conforme se verifica na Ementa do Agravo de Instrumento no 0001019-31.2011.5.02.0016, julgado pela 5ạ Turma, que teve como relator o Ministro Guilherme Augusto Caputo Bastos, publicado em 23 de outubro de 2014, esse direito é inegável: 
AGRAVO DE INSTRUMENTO.

(...) 3. EMPREGADO PÚBLICO DE AUTARQUIA ESTADUAL CONTRATADO SOB O REGIME CELETISTA. EXÉRCIO DE FUNÇÃO COMISSIONADA. SEM RECOLHIMENTO DE FGTS. NÃO PROVIMENTO. Tendo sido o empregado contratado sob o regime celetista, continuando a prestar serviços para a autarquia e recebendo da mesma sua remuneração, mesmo no exercício de cargo em comissão e, por conseguinte, recebendo outros benefícios dai decorrentes, não desobriga a reclamada do recolhimento do FGTS, pois, não tem o condão de transmudar o regime jurídico celetista original dos trabalhadores para o administrativo. Agravo de instrumento a que se nega provimento.

Tal entendimento é predominante na jurisprudência e aceita com frequência pelos Tribunais Regionais do Trabalho, como é o caso do TRT da 15a Região, que em 09 de agosto de 2013 ao julgar caso análogo (Recurso Ordinário no 001885-56.2012.51.5.0076) decidiu, novamente, pelo direito do empregado celetista, comissionado, de receber o FGTS, conforme relatou a Desembargadora Tereza Aparecida Asta Gemignani:

SERVIDOR PÚBLICO. CARGO EM COMISSÃO DE LIVRE NOMEAÇÃO E EXONERAÇÃO. CONTRATAÇÃO PELO REGIME CELETISTA. FGTS DEVIDO. INTELIGÊNCIA DO ART. 15, §§ 10 E 2으, DA LEI 8.036/90. Ao adotar o regime jurídico celetista a Administração Pública reconhece o direito de seus empregados ao recebimento das verbas trabalhistas compatíveis com a natureza da relação jurídica existente. Assim sendo, em relação aos servidores celetistas, mesmo comissionados, o empregador deve observar as regras gerais da legislação pertinente ao FGTS, notadamente porque a exceção ao recolhimento fundiário alcança somente o estatutário, nos termos do $\S 20$ do art. 15 da Lei 8.036/90.

Cumpre ratificar que apenas a multa compensatória devida no caso de dispensa sem justa causa garantida pelo artigo 18, parágrafo único da Lei 8.0360/1990 (40\% sobre o montante dos depósitos mensais devidos) deve ser afastada no caso de destituição injustificada do cargo comissionado, segundo entendimento que ganha corpo na doutrina e jurisprudência.

E é acertado. Sendo de livre exoneração, a indenização que pretende amparar apenas aqueles que são lançados, de surpresa, ao desemprego, gera incompatibilidade com a realidade vivida pelos comissionados, já sabedores da transitoriedade do cargo.

Parecer neste sentido é ilustrado pela Decisão no 029048/1998 do mesmo TRT da 15ạ Região, que teve como relator o Desembargador Luiz Antônio Lazarin:

FGTS. Cargo em comissão. Disciplinando a lei local que o regime jurídico em comissão é o celetista, assiste ao seu ocupante, após a CF/88, direito aos depósitos do FGTS, sem o acréscimo de $40 \%$ a título de multa pela despedida 
arbitrária, a qual, na verdade, inocorre na hipótese de destituição do servidor comissionado.

Não se pode perder de vista que, independente de receber indenização por dispensa do cargo comissionado, as parcelas mensais devem ser pagas pelo empregador, segundo esta corrente de pensamento.

Nesta linha de raciocínio, oportuno se torna destacar que, segundo entendimento dominante, até mesmo quando o contrato de trabalho é declarado nulo por ausência de concurso público, o trabalhador mantém seu direito ao recebimento do FGTS.

Conforme dispõe o artigo 19-A da Lei 8.036/1990, entendimento este consolidado no TST, através do enunciado da súmula 363, reafirma aquela Corte que, embora a contratação de servidor público, sem prévia aprovação em concurso público, não seja permitida, o servidor terá direito "ao pagamento da contraprestação pactuada, em relação ao número de horas trabalhadas, respeitado o valor da hora do salário-mínimo, e dos valores referentes aos depósitos do FGTS".

O TST defendeu em outro julgado este mesmo direito, de o empregado comissionado ter direito aos depósitos fundiários, ao julgar o Recurso de Embargos no 72000-66.2009.5.15.0025, em 02 de outubro de 2014, pela Subseção I, Especializada em Dissídios Individuais, relatado pelo Ministro Augusto César Leite de Carvalho:

Administração Pública. Contratação pelo regime trabalhista. Cargo em comissão de livre nomeação e exoneração. Art. 37, II, da CF. Depósitos do FGTS. Devidos. É assegurado ao servidor público ocupante de cargo em comissão de livre nomeação e exoneração, contratado sob o regime jurídicotrabalhista, o direito aos depósitos do FGTS. O art. 37, II, da CF não autoriza o empregador público a se esquivar da legislação trabalhista a que esteve vinculado o trabalhador no momento da contratação, nem permite concluir que a possibilidade de demissão ad nutum dos ocupantes de cargo em comissão é incompatível com o sistema de proteção social contra a dispensa sem justa causa. De outra sorte, se a Súmula no 363 do TST assegura o direito ao FGTS mesmo diante de uma contratação nula, não se mostra razoável negar o referido direito a quem ingressa regularmente na Administração Pública. Por tais fundamentos, a SBDI-I, por unanimidade, conheceu dos embargos interpostos pelo reclamante, por divergência jurisprudencial, e, no mérito, deu-Ihes provimento para deferir o pagamento do FGTS.

Posto isto, é nítido que o direito ao FGTS não se confunde com o pagamento da indenização devida na dispensa do cargo comissionado sendo, repetimos, pelo entendimento que ganha força nos tribunais regionais do trabalho, com respaldo do seu Tribunal Superior, sempre um direito devido ao funcionário celetista, mesmo que esteja ocupando cargo em comissão. 


\section{CONCLUSÃO}

No decorrer da explanação deste artigo permaneceu nítido que toda pessoa que trabalha amparada pela CLT, tem direito ao recebimento do FGTS. É claro, também, que tal regra poderia comportar alguma exceção prevista em lei, no entanto, inexiste no ordenamento jurídico brasileiro quaisquer referências a possíveis ressalvas.

Não pode ser imposta ao empregado, portanto, uma restrição imaginada pelo empregador, devendo ser observado o princípio da legalidade, vez que "ninguém será obrigado a fazer ou deixar de fazer alguma coisa senão em virtude de lei" (artigo 5, inciso II da Constituição Federal).

Considerando que em nada altera a situação do empregado celetista a nomeação em cargo comissionado e que não há norma que restrinja a contribuição junto ao FGTS nestas situações, sua cessação é ilegal e abusiva.

Ora, o empregador que age desta maneira está ludibriando o lado mais vulnerável da relação trabalhista, tirando-Ihe direito primordial e se esquivando de cumprir suas obrigações, sob a alegação, burlesca, de que o contrato por comissão é incompatível com o pagamento do FGTS, sem nenhum embasamento legal ou justificativa convincente.

Com base em toda a pesquisa doutrinária e jurisprudencial aqui ponderada, conclui-se, enfim, que a nomeação do empregado público para o exercício de cargo em comissão, em nada altera o regime celetista que regulamenta o vínculo empregatício, sendo devido, portanto, todos os direitos a ele inerentes, incluindo os depósitos devidos ao FGTS e esta é a tendência majoritária atual.

\section{REFERÊNCIAS}

ALEXANDRE, R. Direito Administrativo esquematizado. 1. ed. São Paulo: Método, 2015.

BRASIL. Lei 9.962, de 22 de fevereiro de 2000. Brasília: Diário Oficial da União, 2000. Disponível em < http://www.planalto.gov.br/ccivil_03/LEIS/L9962.htm>. Acesso em 30 ago. 2015.

GOMES, F. B. Elementos do Direito Administrativo. 2. ed. São Paulo: Saraiva, 2012.

NADAL, F. Como se preparar para o exame de ordem, 1a fase: administrativo. 12.ed. Rio de Janeiro: Método, 2015.

OLIVEIRA, R. C. R. Curso de Direito Administrativo. 2. ed. São Paulo: Método, 2014.

RESENDE, R. Direito do trabalho esquematizado. 4. ed. São Paulo: Método, 2014.

SANTOS, M. S. Curso de direito administrativo. 1. ed. Rio de Janeiro: Forense, 2013. 
SARAIVA, R. Direito do Trabalho. 15. ed. São Paulo: Método, 2012.

STF. Prazo prescricional para cobrança de valores referentes ao FGTS é de cinco anos. Notícias STF, $13 \quad$ nov. 2014.2 Disponível em <http://www.stf.jus.br/portal/cms/verNoticiaDetalhe.asp?idConteudo=279716>. Acesso em: 30 ago. 2015. 